\title{
La justiciabilidad de los derechos económicos, sociales y culturales: el caso del derecho al agua en la jurisprudencia argentina
}

María de las Nieves Cenicacelaya

\footnotetext{
Doctora en Ciencias Jurídicas y Sociales. Docente investigador, Universidad Nacional de La Plata, La Plata, Argentina. Correo electrónico:

edurneca@yahoo.com.ar
}

Recibido: 2 de julio del 2015

Aprobado: 13 de agosto del 2015

Cómo citar este artículo: María de las Nieves Cenicacelaya. La justiciabilidad de los derechos económicos, sociales y culturales: el caso del derecho al agua en la jurisprudencia argentina. DIXI 22. Diciembre 2015. Pág. 71. doi: http://dx.doi. org/10.16925/di.v17i22.1243

\section{Resumen}

Próposito: con el presente artículo se busca dar noticia de cómo en los últimos tiempos los tribunales argentinos han ido reconociendo el acceso al agua como un derecho fundamental, al acoger los más significativos estándares internacionales en la materia. Descripción: se parte de la premisa según la cual los derechos humanos son universales, indivisibles e interdependientes, sin que sea admisible una supuesta jerarquización de estos. En efecto, se deshecha la idea de que los derechos económicos, sociales y culturales sean, en relación con los derechos civiles y políticos, una suerte de derechos de segunda categoría. Por el contrario, tratándose de derechos absolutamente exigibles - al menos en sus niveles esenciales-, hasta que progresivamente se alcance el más alto nivel posible los Estados tienen, entre otros deberes, la obligación de cumplirlos, lo cual incluye el acceso a las instancias judiciales a fin de garantizar su efectividad. Punto de vista: en este sentido, el artículo se ocupa particularmente del derecho de todo ser humano a disponer de agua segura para uso personal y doméstico, postulando su plena exigibilidad y justiciabilidad. Conclusiones: después de hacer un repaso sobre su reconocimiento normativo interno e internacional, se da cuenta de algunas de las más valorables decisiones de tribunales argentinos que paulatinamente han ido realizando, por vía pretoriana, el derecho humano al agua.

Palabras clave: agua, Argentina, derechos humanos, justicia. 


\title{
Justiciability of Economic, Social and Cultural Rights: The Case of the Right to Water under Argentine Jurisprudence
}

\begin{abstract}
Purpose: This article reports on how Argentine courts have been recognizing access to water as a fundamental right, applying the most significant international standards in that field. Description: Based on the premise that human rights are universal, indivisible and interdependent, and that placing them in a supposed hierarchy is inadmissible. In effect, the Argentine courts discard the idea that economic, social and cultural rights, compared to civil and political rights, could be in a second-class category. On the contrary, because these are rights whose enforcement can absolutely be demanded, at least in their essential levels, states, until they progressively reach the highest possible level, have, among other duties, the obligation to fulfill them, which includes access to the courts to guarantee their effectiveness. Point of view: In this sense, the article primarily focuses on the right of all human beings to have safe water for personal and domestic use, postulating its full enforceability and justiciability. Conclusions: After a review of its internal and international legal and regulatory recognition, the article shows how some of the most valuable rulings by Argentine courts have gradually strengthened the human right to water.
\end{abstract}

Keywords: water, Argentina, human rights, justice.

\section{A justiciabilidade dos direitos econômicos, sociais e culturais: o caso do direito à água na jurisprudência argentina}

\section{Resumo}

Propósito: o presente artigo visa apresentar como, nos últimos tempos, os tribunais argentinos foram reconhecendo o acesso à água como um direito fundamental ao adotarem os mais significativos padrões internacionais na matéria. Descrição: parte-se da premissa segundo a qual os direitos humanos são universais, indivíveis e interdependentes, sem que seja admissível uma suposta hierarquização destes. Na verdade, descarta-se a ideia de que os direitos econômicos, sociais e culturais sejam, com relação aos direitos civis e políticos, uma espécie de direitos de segunda categoria. Pelo contrário, tratando-se de direitos absolutamente exigíveis - pelo menos em seus níveis essenciais-, até que progressivamente se alcance o mais alto nível possível, os Estados têm, entre outros deveres, a obrigação de cumpri-los, o que inclui o acesso às instâncias judiciais a fim de garantir sua efetividade. Ponto de vista: nesse sentido, o artigo ocupa-se particularmente do direito de todo ser humano a dispor de água segura para uso pessoal e doméstico, e postula sua plena exigibilidade e justiciabilidade. Conclusões: após uma revisão sobre seu reconhecimento normativo interno e internacional, percebem-se algumas das mais valiosas decisões de tribunais argentinos que paulatinamente foram realizando, por via pretoriana, o direito humano à água.

Palavras-chave: água, Argentina, direitos humanos, justiça. 


\section{INTRODUCCIÓN}

Hacia el fin de la II Guerra Mundial, con la adopción de la Declaración Universal de Derechos Humanos en 1948 se daba inicio a un ambicioso proceso consistente en que los Estados se comprometieran a garantizar los derechos fundamentales de todas las personas sujetas a su jurisdicción, así como que su desconocimiento comportara su responsabilidad internacional. El sistema - universal y regionalmente- se desarrolló y perfeccionó de manera tal que cada vez más derechos fueron reconocidos, más personas estuvieron protegidas y más obligaciones asumieron los Estados.

Sin embargo, si bien desde hace varias décadas en todos los ámbitos (científico, académico y político) se asume la evidencia de que acceder a agua segura es una necesidad vital, el reconocimiento del acceso al agua como derecho humano es aún hoy muy restringido. En efecto, ningún instrumento internacional sobre derechos humanos lo consagra expresa y autónomamente, y sólo unas pocas constituciones estatales lo hacen. Como consecuencia de ello, su protección judicial es todavía muy incipiente.

Por esto, a continuación, luego de repasar algunas ideas clave en materia de derechos humanos en general, y de derechos económicos, sociales y culturales en particular, así como de reafirmar su plena exigibilidad y justiciabilidad, el artículo examina con atención el caso del derecho al agua, focalizándose finalmente en las respuestas que han ido produciendo los jueces argentinos de diversas instancias y fueros en procura de la realización de este derecho fundamental.

\section{LOS DERECHOS HUMANOS}

La idea de los derechos humanos -invención surgida a partir de las revoluciones burguesas del Atlántico Norte de fines del siglo XVIII ${ }^{1}$ - nació con una marcada impronta liberal, en la forma de libertades individuales que exigen la autolimitación y la no injerencia de los poderes públicos en la esfera privada, y las cuales se tutelan por su mera actitud pasiva y abstencionista. Esa matriz ideológica sufriría un proceso de erosión e impugnación durante el siglo XIX que evidenciará la necesidad de complementar esas primeras libertades con los derechos

1. Véase Lynn Hunt. LA InVENCIÓN DE LOS DEREChos humanos. Tusquets. (2010). económicos, sociales y culturales, ${ }^{2}$ los cuales requieren de políticas públicas activas, promotoras, "removedoras" de obstáculos, en términos del artículo 3 de la Constitución Italiana de $1947 .^{3}$

Más tarde, ya en pleno siglo $\mathrm{xx}$, las profundas divisiones ideológicas del mundo durante la denominada "guerra fría" condujeron a la fragmentación del corpus iuris de los derechos humanos, ignorando la perspectiva holística emanada de la Declaración Universal de Derechos Humanos de 1948 — piedra angular del sistema internacional de protección de estos derechos ${ }^{4}$ - así como a un "etiquetamiento" (labeling) ${ }^{5}$ y una compartimentación entre los derechos civiles y políticos (denominados de primera generación), por un lado, y los derechos económicos, sociales y culturales (denominados de segunda generación), por otro. En este sentido, la adopción en el seno de la Organización de las Naciones Unidas en 1966 de dos instrumentos internacionales (a saber, el "Pacto Internacional de Derechos Civiles y Políticos" y el "Pacto Internacional de Derechos Económicos, Sociales y Culturales"), ${ }^{6}$ contribuyó a que algunos plantearan cómo ese distinto reconocimiento de las dos categorías de derechos humanos se fundaba en diferencias de naturaleza, lo que importaría, además, una especie de jerarquización entre ellos. ${ }^{7}$

Estas especulaciones llevaron a que la primera Conferencia Internacional de Derechos Humanos, celebrada en Teherán en 1968, se pronunciara expresamente al respecto aduciendo que dado que los derechos humanos y las libertades fundamentales son universales, indivisibles e interdependientes, resulta imposible la realización de los derechos civiles y políticos sin el goce de los derechos económicos, sociales y culturales. ${ }^{8}$

2. Véase Antonio Enrique Pérez Luño. Concepto y concepción de los derechos humanos. Revista Doxa 4. 1987. Págs. 47-66.

3. "Es obligación de la República remover los obstáculos de orden económico y social que, limitando de hecho la libertad y la igualdad de los ciudadanos, impidan el pleno desarrollo de la persona humana". Véase Constitución de la República Italiana [Const.]. Art. 3. 1947. (Italia).

4. Ibrahima Fall. La protección de los derechos humanos en el horizonte del Siglo XXI. Revista DE RELACIONES InTERnACIONALES 8. 1995. Págs. 23-48

5. Véase Carlos Urquilla. La JUSTiCiabilidad DiRECTA DE LOS DERECHOS ECONÓMICOS, SOCIALES Y CULTURALES. Instituto Interamericano de Derechos Humanos. (2008).

6. Véase u.n. Pacto Internacional de Derechos Civiles y Políticos. A/REs/21/2200. (1966).

7. Véase Karel Vasak. Les mysterieux droits economiques de l'homme. Comp. Renato Zerbini Ribeiro. Rumbos DeL DERECHO INTERNACIONAL DE LOS DERECHOS hUMANOS. Tomo III. (2005). Págs. 253-265

8. Véase Proclamación de Teherán, punto 13. 
Son universales porque al ser inherentes a la condición humana, les son debidos a todos y cada uno de los hombres en todo Estado por todos los Estados, independientemente del régimen político, social o cultural que sostengan. ${ }^{9} \mathrm{Y}$, tal como manifiesta el Protocolo de San Salvador, considerando la estrecha relación que existe entre todos los derechos, se impone una tutela y promoción permanente a fin de lograr su vigencia plena, sin que pueda justificarse jamás la violación de unos en aras de la realización de otros. ${ }^{10}$

Años después, la cuestión fue abordada por el relator especial de las Naciones Unidas, Danilo Turk, en su informe sobre la realización de los derechos económicos, sociales y culturales. ${ }^{11}$ En este, con toda contundencia, se pronunció sobre la imposibilidad de establecer jerarquías de derechos. Todos los derechos humanos tienen un mismo origen, un mismo titular y un mismo destinatario, sostuvo. Todos emanan de la dignidad esencial del ser humano, constituyen un ideal común de la humanidad, pertenecen a todos los miembros de la familia humana y son, por tanto - concluía - reclamables al Estado, obligado a su promoción y protección.

En igual sentido se pronunció la segunda "Conferencia Mundial de Derechos Humanos" desarrollada durante el mes de junio de 1993 en Viena, al postular que todos "los Estados tienen el deber, sean cuales fueren sus sistemas políticos, económicos y culturales, de promover y proteger todos los derechos humanos y las libertades fundamentales". ${ }^{12}$

Siguiendo esta misma línea argumental, en el ámbito regional es pertinente recordar un voto concurrente y razonado del juez de la Corte Interamericana de Derechos Humanos, Sergio García Ramírez, en el cual advierte que los derechos humanos son,

Todos relevantes, exigibles, mutuamente complementarios y condicionados [...] Todos son, de una sola vez, el escudo protector del ser humano: se reclaman, condicionan y perfeccionan mutuamente, y por ende es preciso brindar a todos la misma atención.

9. Véase Pedro Nikken. El concepto de derechos humanos. Estudios BÁSICOS DE DERECHOS HUMANOS. Tomo I. Instituto Interamericano de Derechos Humanos. (1994). Págs. 15-37.

10. Véase Convención Americana sobre Derechos Humanos (CAdh). Preámbulo. Protocolo Adicional a la Convención Americana sobre Derechos Humanos en materia de Derechos Económicos, Sociales y Culturales. (Noviembre 17 de 1988)

11. Véase u.n. Danilo Türk. The Realization of EConomic, SOCIAL AND CUltural RIGHTS. E/CN.4/Sub.2/1992/16. (Julio 3 de 1992).

12. Véase U.n. Declaración y Programa de Acción de Viena. A/CONF.157/23. (Julio 12 de 1993). Parte I, párrafo 5.
No podríamos decir que la dignidad humana se halla a salvo donde existe, quizás, esmero sobre los derechos civiles y políticos - o sólo algunos de ellos, entre los más visibles- y desatención acerca de los otros. ${ }^{13}$

\section{LOS DERECHOS ECONÓMICOS, SOCIALES Y CULTURALES}

Descartada toda duda respecto a que sea posible sostener la existencia de unos derechos de mayor nivel o más importantes que otros, no cabe admitir que los derechos económicos, sociales y culturales sean en la práctica "derechos de segunda clase" ${ }_{1}^{14}$ inaplicables, no sometidos a los tribunales y que sólo se irán cumpliendo "progresivamente" con el tiempo.

Ahora bien, postular la indivisibilidad e interdependencia de los derechos no evita tener en cuenta las diferencias en relación con el modo de ejercicio y las obligaciones de los Estados respecto a los distintos derechos humanos. ${ }^{15}$

En los derechos civiles y políticos las obligaciones de los Estados son básicamente de resultado, de abstención, de no hacer; es su actividad en contrario la que produce la violación del derecho. En tanto que en los económicos, sociales y culturales predominan las obligaciones de comportamiento, en las cuales su realización no depende en general de la sola instauración de un orden jurídico, ni de la mera decisión política de los gobiernos, sino de la conquista de un orden social en el que impere una justa distribución de los bienes, lo cual —es indudable - sólo puede alcanzarse progresivamente. ${ }^{16}$

Esto no implica que pueda postularse la no exigibilidad de los derechos económicos, sociales y culturales ${ }^{17}$ por tratarse de derechos vagos y evanescentes

13. Véase Corte Interamericana de Derechos Humanos. Condición Jurídica y Derechos Humanos del Niño. Opinión Consultiva oc-17/02. (Agosto 28 de 2002).

14. Véase Ligia Bolívar. Derechos económicos, sociales y culturales: derribar mitos, enfrentar retos, tender puentes. Estudios BÁsicos DE DeRechos humanos. Tomo v. Instituto Interamericano de Derechos Humanos. (1996). Págs. 86-136.

15. Véase Fabián Salvioli. Algunas tendencias sobre derechos humanos en las relaciones internacionales y el derecho internacional de la posguerra fría. Anuario de Relaciones Internacionales 1995/96. Centro de Estudios Avanzados, Universidad de Córdoba. (1997). Págs. 21-80.

16. Véase Pedro Nikken. La protección internacional de LOS DERECHOS HUMANOS: SU DESARROLLO PROGRESIVO. Instituto Interamericano de Derechos Humanos. Civitas. (1987).

17. Véase Mónica Pinto. Los derechos económicos, sociales y culturales y su protección en el sistema universal y en el sistema 
o que prometen poco, o que de esa indeterminación se deduzca, acaso, un principio programático, una guía de actuación para los poderes públicos, pero no un auténtico derecho.

Es necesario dejar en claro que por el hecho de que la norma que los contenga sea programática, ello no conduce a que se trate de una mera declamación retórica del Estado, pues esto llevaría a sostener que este está eximido del cumplimiento de la obligación esencial e inmediata ${ }^{18}$ - la cual no está condicionada ni limitada por ninguna otra consideración ${ }^{19}-$ de "adoptar medidas" a fin de lograr la plena efectividad de esos derechos. ${ }^{20}$ Una posición semejante descansa en prejuicios ideológicos que siguen diferenciando entre los derechos civiles y políticos, por un lado, y los económicos, sociales y culturales, por otro, y en la que sólo los primeros serían auténticamente exigibles.

Además, no es que los derechos civiles y políticos generen únicamente obligaciones negativas o de abstención en tanto que los derechos económicos, sociales y culturales impliquen solamente obligaciones positivas de hacer y sobre todo de dar. ${ }^{21}$ Por el contrario, es factible encontrar derechos civiles y políticos en los que se requiere que el Estado haga algo en favor del individuo (obligaciones positivas), los cuales van desde la realización de un acto concreto, hasta la creación de normas e instituciones cuyo propósito es hacer efectivo el goce de los derechos respectivos. De igual forma, se encuentran derechos económicos, sociales y culturales que implican un deber de no hacer $y$, por tanto, de respeto al derecho protegido.

Las obligaciones estatales en torno a los derechos económicos, sociales y culturales han sido estructuradas de un modo tripartito, a partir de una idea formulada por Asbjørn Eide - relator especial de las Naciones Unidas- sobre el derecho a la alimentación, ${ }^{22}$ las cuales la jurisprudencia del Comité

interamericano. Revista DEL INSTITUTO INTERAMERICANO DE Derechos Humanos. (Vol. 40, 2004). Págs. 25-86.

18. Véase Susana Albanese. Indivisibilidad e interdependencia de los derechos. Coord. Germán Bidart Campos. EconomíA, CONSTITUCión y DERECHOS Sociales. Ediar. (1997). Págs. 9-39.

19. Véase Philippe Texier. Exigibilidad de los derechos económicos, sociales y culturales en el sistema universal. CONSTRUYENDO UNA AGENDA PARA LA JUSTICIABILIDAD DE LOS DERECHOS SOCIALES. CEJIL. (2004). Págs. 13-24.

20. Cf. U.N. supra, nota 6. Artículo 2.1; Convención Americana sobre Derechos Humanos-Pacto de San Juan de Costa Rica (Noviembre 22 de 1969). Artículo 26; y Convención Americana sobre Derechos

Humanos (CADH), supra, nota 10. Artículo 1.

21. Véase Víctor Abramovich y Christian Courtis. Los Derechos SOCIALES COMO DERECHOS EXIGIBLES. Trotta. (2002).

22. Véase U.N. Commission on Human Rights. The Right to FOOD. E/CN.4/sub.2/1987/23. (Marzo 7 de 1988). de Derechos Económicos, Sociales y Culturales de las Naciones Unidas ha consolidado. Así, el Estado tiene las siguientes obligaciones:

1. Obligación de respetar. Es un deber de carácter negativo consistente en no lesionar los derechos, por ejemplo, absteniéndose de ejecutar actos que importen la privación de un derecho o evitando actos de discriminación en relación con el goce de cualquiera de los derechos.

2. Obligación de proteger. Implica que el Estado debe adoptar medidas legislativas o de otro carácter destinadas a impedir que terceros (particulares, empresas) interfieran, obstaculicen o menoscaben en modo alguno el disfrute de un derecho económico, social o cultural.

3. Obligación de cumplir. El Estado debe dar plena efectividad a los derechos económicos, sociales y culturales. Esta obligación genérica se divide a su vez en otras tres obligaciones específicas:

- Facilitar. Adoptando medidas positivas que permitan y ayuden a los particulares a ejercer estos derechos.

- Promover. Adoptando medidas para difundir información de manera adecuada sobre estos derechos.

- Garantizar. Haciendo efectivos estos derechos cuando los particulares no están en condiciones - por razones ajenas a su voluntad- de ejercerlos por sí mismos con los medios a su disposición. Se incluye aquí la posibilidad jurídica formal y material del titular del derecho para acudir ante alguna instancia judicial, a fin de que en caso de incumplimiento se le satisfaga en el goce efectivo de su derecho.

Por otra parte, es necesario dejar en claro que si bien la plena realización de los derechos económicos, sociales y culturales, a tenor de lo dispuesto tanto por el pacto internacional correspondiente, como por la Convención Americana sobre Derechos Humanos y su Protocolo Adicional en materia de Derechos Económicos, Sociales y Culturales, ${ }^{23}$ puede lograrse de manera paulatina y gradual, ${ }^{24}$ las medidas tendientes

23. Cf. A.G. Res. 2200A (xxi). Pacto Internacional de Derechos Económicos, Sociales y Culturales. (Enero 3 de 1976). Artículo 2.1; Convención Americana sobre Derechos Humanos-Pacto de San Juan de Costa Rica, supra, nota 22. Artículo 26; Convención Americana sobre Derechos Humanos (CADH), supra, nota 11. Artículo 1.

24. Véase Christian Courtis. La prohibición de regresividad en materia de derechos sociales: apuntes introductorios. Comp. Christian Coutis. Ni UN PASO ATRÁs. LA PROHIBICIÓN DE REGRESIVIDAD EN MATERIA DE DERECHOS SOCIALES. CELS, Editores del Puerto. (2006). Págs. 6-58. 
a lograr este objetivo deben adoptarse dentro de un plazo razonablemente breve tras la entrada en vigor del respectivo instrumento en el Estado involucrado. ${ }^{25}$ Progresivamente no puede significar postergación sine die, sino avanzar continuamente. ${ }^{26}$ Más aún, como surge expresamente de los "Principios de Limburgo", ${ }^{27}$ la obligación de "lograr progresivamente [...] la plena efectividad de los derechos" requiere que los Estados partes actúen con toda la rapidez posible con el fin de lograr la efectividad de los derechos. En consecuencia, el carácter progresivo de las normas no altera las obligaciones del Estado.

Tales deberes implican que algunas medidas se tomen de manera inmediata (adoptar medidas, no discriminar, respetar el contenido mínimo y esencial del derecho), o tan pronto sea posible deben estar todas ellas orientadas lo más claramente posible hacia la satisfacción de las obligaciones asumidas por el Estado. ${ }^{28} \mathrm{Y}$ también, según los "Principios de Limburgo", deben desarrollar dentro de la sociedad los recursos que sean necesarios a fin de lograr la plena realización de los derechos económicos, sociales y culturales para todas las personas. ${ }^{29}$

Sin embargo, la naturaleza progresiva de las obligaciones asumidas por los Estados en materia de derechos económicos, sociales y culturales ha conducido a que algunos sostengan que carecen de justiciabilidad. ${ }^{30}$ Esto iría contra la indivisibilidad e interdependencia de los derechos humanos e incluso contra la regla general de interpretación de los

25. Véase Comité Desc. Observación General N. ${ }^{\circ}$ 3. La índole de las obligaciones de los Estados Partes Párrafo 1 del artículo 2 del Pacto). Observaciones Generales adoptadas por el Comité de Derechos Económicos, Sociales y Culturales. (1990). Párrafo 2.

26. Véase Magdalena Sepúlveda. La interpretación del Comité de Derechos Económicos, Sociales y Culturales de la expresión "progresivamente". NI UN PASO ATRÁs. LA PROHIBICIÓN DE REGRESIVIDAD EN MATERIA DE DERECHOS SOCIALES. CELS, Editores del Puerto. (2006). Págs. 117-150

27. Los "Principios de Limburgo sobre la Aplicación del Pacto Internacional de Derechos Económicos, Sociales y Culturales" es un documento surgido de un grupo de expertos en el campo del Derecho Internacional, reunidos en la Facultad de Derecho de la Universidad de Limburgo (Maastricht, Países Bajos), entre el 2 y el 6 de junio de 1986 con el propósito de considerar la naturaleza y el alcance de las obligaciones de los Estados Partes del PIDEsc que fue adoptado luego por Naciones Unidas. Véase U.N. LIMBURG PRINCIPLES ON THE IMPLEMENTATION OF THE INTERNATIONAL COVENANT ON ECONOMIC, SOCIAL AND CULTURAL RIGHTS. E/CN.4/1987/17. (1987).

28. Véase Comité DEsc, supra, nota 27. Párrafo 9.

29. Véase u.n. Limburg Principles on the Implementation of the International Covenant on Economic, Social and Cultural Rights, supra, nota 27. Principio 24.

30. Véase Mónica Pinto, supra, nota 19. tratados conforme a la Convención de Viena sobre el Derecho de los Tratados de 1969, ${ }^{31}$ la cual se recuerda en los Principios de Limburgo. ${ }^{32}$

Afirmar la justiciabilidad de los derechos económicos, sociales y culturales tiene como consecuencia que existan derechos genuinos y no meras expectativas de derechos, promesas o esperanzas, así como que converjan seriamente con su contrapartida jurídica deberes auténticos que, por serlo, pueden ser activados por medio de la pretensión de tutela acogida en la sentencia. ${ }^{33}$

De lo contrario, se estaría vulnerando la garantía genérica del acceso a la justicia que, con diferentes denominaciones, aparece consagrada en varios instrumentos internacionales sobre derechos humanos. ${ }^{34} \mathrm{Y}$ si bien la tutela jurisdiccional no es la única posible, ni tampoco la única deseable, ${ }^{35}$ al existir otras fórmulas eficaces para promover y garantizar los derechos humanos, ${ }^{36}$ el acceso a la justicia sí es, en opinión del Comité de Derechos Económicos, Sociales y Culturales, ${ }^{37}$ y de la Comisión Interamericana de Derechos Humanos, un componente fundamental para garantizar el goce de los derechos económicos, sociales y culturales, el cual debe comprender la obligación de los Estados de remover obstáculos económicos a fin de garantizar el acceso a los tribunales, cuidar del debido proceso y de la tutela judicial efectiva. La obligación del Estado es, en este sentido, no sólo negativa — no impedir el acceso- sino también positiva, de manera que debe organizar el aparato institucional para que todos puedan acceder. ${ }^{38}$

31. Véase U.N. Comisión de Derecho internacional. Convención DE Viena SOBRE El DERECHO DE LOS TRATAdos. A/CONF.39/27 (1969). Artículo 31.1.: "Un tratado deberá interpretarse de buena fe conforme al sentido corriente que haya de atribuirse a los términos del tratado en el contexto de estos y teniendo en cuenta su objeto y fin".

32. Cf. u.n. Limburg Principles on the Implementation of the International Covenant on Economic, Social and Cultural Rights, supra, nota 27. Principios 4 y 7.

33. Véase Sergio García Ramírez. Protección jurisdiccional internacional de los derechos económicos, sociales y culturales. Cuestiones Constitucionales 9. 2003. Págs. 127-157.

34. Véase U.N. Res. 217A (III). Declaración universal DE Derechos humanos. (Diciembre 10 de 1948). Artículo 8, Artículo XVIII; OEA. DECLARACIÓN AMERICANA DE DERECHOS Y DEBERES Del hombre. (1948). Artículo 14.1; u.n. Pacto Internacional de Derechos Civiles y Políticos, supra, nota 6. Artículo 14.1; Convención Americana sobre Derechos Humanos (CADH), supra, nota 11. Artículos 8.1 y 25.1.

35. Véase Sergio García Ramírez, supra, nota 33.

36. Por ejemplo, los Ombudsmen, Comisiones Nacionales de Derechos Humanos o Entes Reguladores.

37. Véase Comité DEsc, supra, nota 25. Párrafo 5.

38. Véase CidH. Informe del Comisionado Víctor Abramovich

SOBRE EL ACCESO A LA JUSTICIA COMO GARANTÍA DE LOS 
El carácter indeterminado del contenido de un derecho también puede ser un obstáculo para su exigibilidad. Sin ser una justificación válida, la vaguedad en su definición dentro de los textos normativos y/o la inexistencia o la deficiencia de los instrumentos procesales que existen para reclamar o reparar las violaciones respectivas, pueden conspirar contra la exigibilidad de los derechos económicos, sociales y culturales. Pero estas cuestiones en realidad no son males irreparables, toda vez que con voluntad política dichos problemas pueden ser salvados.

Dicha indeterminación lleva a preguntarse por el contenido esencial, mínimo, sin el cual el derecho pierde su significación. El Comité de Derechos Económicos, Sociales y Culturales sostiene que corresponde a cada Estado parte del pacto homónimo, "una obligación mínima de asegurar la satisfacción de por lo menos niveles esenciales de cada uno de los derechos", pues si el "pacto se ha de interpretar de tal manera que no establezca una obligación mínima, carecería en gran medida de su razón de ser. ${ }^{39} \mathrm{El}$ contenido esencial de un derecho señala una frontera inquebrantable bajo pretexto de razón alguna, un límite para la acción discrecional del Estado y el piso a partir del cual se deberá ir desarrollando progresivamente el más alto nivel posible.

Los Estados asumen el compromiso de satisfacer los derechos económicos, sociales y culturales "hasta el máximo de los recursos disponibles" según el Pacto Internacional de Derechos Económicos, Sociales y Culturales, ${ }^{40}$ y el Protocolo Adicional a la Convención Americana sobre Derechos Humanos en materia de Derechos Económicos, Sociales y Culturales (Protocolo de San Salvador), ${ }^{41}$ los cuales mejoran, con creces, la redacción de la Convención Americana sobre Derechos Humanos que sólo obliga "en la medida de los recursos disponibles". ${ }^{42}$ Así, la realización de los derechos tutelados por estos instrumentos representa una prioridad jurídicamente definida cuyo desconocimiento en la práctica es ilegítimo, ${ }^{43}$ pues debe ponerse un énfasis especial en la asignación de recursos para estas áreas por encima

DERECHOS ECONÓMICOS, SOCIALES Y CULTURALES. ESTUDIO DE LOS ESTÁNDARES FIJADOS POR EL SISTEMA INTERAMERICANO De Derechos Humanos. Oea/Ser.L/V/II.129 DoC. 4. (Septiembre 7 de 2007)

39. Véase Comité DEsc, supra, nota 25. Párrafo 10.

40. Cf. A.G. Res. 2200A (xxi), supra, nota 23. Artículo 2.1.

41. Cf. Convención Americana sobre Derechos Humanos (CADH), supra, nota 10. Artículo 1.

42. Cf. Convención Americana sobre Derechos Humanos-Pacto de San Juan de Costa Rica, supra, nota 20. Artículo 26.

43. Véase Pedro Nikken, supra, nota 16 de otras en el presupuesto, de manera que la falta de recursos en ningún caso puede justificar su incumplimiento, siendo siempre carga del Estado justificar su inactividad. ${ }^{44}$

En relación con esto, se impone, además, superar la visión según la cual sólo los derechos económicos, sociales y culturales necesitan de cuantiosos recursos económicos. Todos los derechos requieren financiamiento. No existen derechos de "costo cero". 45

\section{EL DERECHO AL AGUA}

Al igual que el aire, el agua se consideró tan fundamental para la vida que su inclusión expresa se creyó innecesaria al momento de adoptarse la Declaración Universal de Derechos Humanos. No obstante, puede argumentarse, sin duda, que el agua está incluida implícitamente en el instrumento que ha constituido la piedra de angular de la tutela internacional de los derechos humanos, cuando protege el derecho a un nivel de vida adecuado. ${ }^{46}$

En el sistema onusiano sólo se menciona explícitamente en dos tratados, aunque sin carácter de autonomía. En efecto, se incluye el acceso al agua, por un lado, en la Convención sobre la Eliminación de todas las Formas de Discriminación contra la Mujer, en relación con el derecho a gozar de condiciones de vida adecuada, ${ }^{47}$ y, por otro, en la Convención sobre los Derechos del Niño, en conexión con el derecho a la salud. ${ }^{48}$ Del mismo modo, también vinculándolo a los derechos a un nivel de vida adecuado y a la salud, el derecho al agua aparece implícito en dos disposiciones del Pacto Internacional de Derechos Económicos, Sociales y Culturales. ${ }^{49}$

En similar sentido, en el ámbito americano, lo contempla de modo no expreso y en conexión con el derecho a la salud y a un ambiente sano, el "Protocolo Adicional a la Convención Americana sobre Derechos Humanos en materia de Derechos Económicos, Sociales y Culturales", o "Protocolo de San Salvador". ${ }^{50}$

\footnotetext{
44. Cf. Directrices de Maastricht 8 y 13.

45. Véase Cristina Monereo. Una teoría de los derechos sociales es posible. Herramientas para la Defensa de los Derechos ECONÓMiCOS, SOCIALES Y CUlTuRALEs. (2006). Págs. 9-27.

46. Cf. U.N. Res. 217A(III), supra, nota 34. Artículo 25

47. Cf. U.N. Comisión de la Condición Jurídica y Social de la Mujer. CONVENCIÓN SOBRE LA ELIMINACIÓN DE TODAS LAS FORMAS DE DISCRIMINACIÓN CONTRA LA MUJER. (1946). Artículo 14.2.h. 48. Cf. Artículo 24.2.c.

49. Cf. A.G. Res. 2200A(xxi), supra, nota 23. Artículos 11.1 y 12.1. 50. Cf. Convención Americana sobre Derechos Humanos-Pacto de San Juan de Costa Rica, supra, nota 20. Artículos 10.1 y 11.1.
} 
Por su parte, el 26 de noviembre del 2002, el Comité de Derechos Económicos, Sociales y Culturales publicó su "Observación General N. ${ }^{\circ}$ 15, El derecho al agua” (artículos 11 y 12 del Pacto Internacional de Derechos Económicos, Sociales y Culturales), trascendente documento en el que se consigna que "el derecho humano al agua es indispensable para vivir dignamente" y que este "es condición previa para la realización de otros derechos humanos". ${ }^{51}$

Dicho comité considera, además, que se trata de un derecho reconocido por el Pacto Internacional de Derechos Económicos, Sociales y Culturales, el cual implica que todas las personas dispongan de "agua suficiente, salubre, aceptable, accesible y asequible para el uso personal y doméstico". ${ }^{52} \mathrm{Y}$ en relación con el contenido normativo establece que,

El derecho al agua entraña tanto libertades como derechos. Las libertades incluyen mantener el acceso a un suministro de agua necesario para ejercer el derecho al agua y el derecho a no ser objeto de injerencias, como por ejemplo, a no sufrir cortes arbitrarios del suministro o a la no contaminación de los recursos hídricos. En cambio, los derechos comprenden el acceso a un sistema de abastecimiento y gestión del agua que ofrezca a la población iguales oportunidades de disfrutar del derecho al agua. ${ }^{53}$

Especificando lo que para los derechos económicos, sociales y culturales en general ya se había explicado en torno al contenido mínimo o esencial del derecho, ${ }^{54}$ el Comité de Derechos Económicos, Sociales y Culturales señala que el derecho humano al agua implica en cualquier circunstancia los siguientes componentes: disponibilidad, ${ }^{55}$ calidad, ${ }^{56}$ accesibilidad física y económica, ${ }^{57} \mathrm{y}$ no discriminación. ${ }^{58}$

Así como ocurre con todos los derechos humanos, ${ }^{59}$ respecto al derecho al agua, según el

51. Véase Comité DESC, supra, nota 25. Observación General N. ${ }^{\circ} 15$, "El derecho al agua" (artículos 11 y 12 del Pacto Internacional de Derechos Económicos, Sociales y Culturales), 2002. Párrafo 1.

52. Id. Párrafo 2.

53. Id. Párrafo 10

54. Véase Comité DEsc, supra, nota 25. Párrafo 10.

55. Véase Comité DESC, supra, nota 25. Observación General N. ${ }^{\circ} 15$,

"El derecho al agua" (artículos 11 y 12 del Pacto Internacional de Derechos Económicos, Sociales y Culturales), 2002, párrafo 12.a.

56. Id. Párrafo 12.b.

57. Id. Párrafos 12.c, 15 y 27

58. Id. Párrafo 13

59. Véase Comité DEsc, supra, nota 25. Observación General N. ${ }^{\circ} 12$ "El derecho a una alimentación adecuada (artículo 11)", 1999, párrafo 15 . mencionado comité, las obligaciones de los Estados partes son de tres tipos, a saber:

1. Respetar. Entre otras, son violaciones a esta obligación de respetar: la interrupción o desconexión arbitraria o injustificada de los servicios o instalaciones de agua; los aumentos desproporcionados o discriminatorios del precio del agua; y la contaminación y disminución de los recursos de agua en detrimento de la salud del humano.

2. Proteger. Las violaciones a este deber incluyen, entre otras, no hacer cumplir las leyes que tengan por objeto evitar la contaminación y la extracción no equitativa del agua; no regular ni controlar eficazmente los servicios de suministro de agua explotados o controlados por terceros a través de una supervisión independiente, una auténtica participación pública y la imposición de multas por incumplimiento; no tutelar los sistemas de distribución de agua (por ejemplo, las redes de canalización y los pozos) de la injerencia indebida, el daño y la destrucción.

3. Cumplir o realizar. El Estado debe garantizar el disfrute del derecho al agua para todas las personas, lo cual implica hacer efectivo este derecho "en los casos en que los particulares o los grupos que no están en condiciones - por razones ajenas a su voluntad- de ejercer por sí mismos ese derecho con los medios a su disposición". 60

Además, este deber también incluye reconocer en grado suficiente este derecho en la normativa político-jurídica nacional, incorporando en el ordenamiento jurídico interno los instrumentos internacionales en los que se reconoce el derecho al agua y facilitando el acceso a la justicia en casos de violaciones, mediante la creación de mecanismos procesales adecuados que permitan a las personas y/o grupos acudir ante los tribunales a fin de defender este derecho. En este sentido, el Comité de Derechos Económicos, Sociales y Culturales ha reconocido expresamente que "toda persona o grupo que haya sido víctima de una violación del derecho al agua deberá contar con recursos judiciales o de otro tipo efectivos tanto en el plano nacional como en el internacional"; así como "todas las víctimas de las violaciones del derecho al agua deberán tener derecho a una reparación adecuada, que podrá consistir en restitución, indemnización, satisfacción o garantías de que no se repetirán los hechos". ${ }^{61}$

60. Id. Párrafo 25.

61. Id. Párrafo 55. 
A su turno, el 28 de julio de 2010, la Asamblea General de las Naciones Unidas, después de manifestar su profunda preocupación porque millones de personas carecen de acceso al agua potable y al saneamiento básico, de reconocer la importancia de disponer de ambos como componente integral de la realización de todos los derechos humanos y teniendo presente el compromiso contraído por la comunidad internacional de cumplir plenamente los "Objetivos de Desarrollo del Milenio" (ODM) ${ }^{62}$ declaró, a través de una histórica resolución propuesta por el representante de Bolivia, copatrocinada por otros 37 Estados miembros de la organización ${ }^{63}$ y adoptada por 122 votos a favor, ninguno en contra y 41 abstenciones, el acceso al agua potable y a los servicios sanitarios básicos como derechos humanos básicos.

Precisamente, uno de los objetivos en cuestión, el séptimo, que se orientaba a "garantizar la sostenibilidad del medio ambiente", establecía varias metas. Entre estas, la más directamente relacionada con nuestra problemática, la de "reducir a la mitad, para el año 2015, y respecto a 1990, el porcentaje de personas sin acceso sostenible a agua potable". Esto significaba facilitar el acceso a agua segura a alrededor de 274000 y personas más cada día.

Si bien el mundo alcanzó la meta relativa al acceso al agua potable anticipadamente - en el 2012, el $90 \%$ de la población mundial disponía de fuentes mejoradas de agua, en comparación con el $76 \%$ en 1990-, los progresos, sin embargo, han sido desiguales en las diferentes regiones entre las zonas urbanas

62. Acuerdo alcanzado en el seno de la Asamblea General de las Naciones Unidas, en el 2000, por 147 jefes de Estado y de Gobierno con el fin de llevar adelante una serie de tareas para liberar a las poblaciones menos desarrolladas de las trabas de la pobreza extrema, el hambre, el analfabetismo y las enfermedades. El compromiso se formalizó en una declaración aprobada por 189 países, la cual se estructuró en ocho objetivos (erradicar la pobreza extrema y el hambre; lograr la enseñanza primaria universal; promover la igualdad de género y el empoderamiento de la mujer; reducir la mortalidad infantil; mejorar la salud materna; combatir el VIH/sIDA, el paludismo y otras enfermedades; garantizar la sostenibilidad del medio ambiente; y fomentar una alianza mundial para el desarrollo), con dieciocho metas, todos estrechamente relacionados y complementados entre sí, que deberían ser alcanzados, como fecha límite, en el 2015. Sin embargo, en el 2007, se incorporaron cuatro nuevas metas acordadas por los Estados miembros en la Cumbre Mundial de 2005.

63. Estos son: Angola, Antigua y Barbuda, Arabia Saudita, Azerbaiyán, Baréin, Bangladés, Benín, Eritrea, el Estado Plurinacional de Bolivia, Burundi, Congo, Cuba, Dominica, Ecuador, El Salvador, Fiji, Georgia, Guinea, Haití, Islas Salomón, Madagascar, Maldivas, Mauricio, Nicaragua, Nigeria, Paraguay, República Centroafricana, República Dominicana, Samoa, San Vicente y las Granadinas, Santa Lucía, Serbia, Seychelles, Sri Lanka, Tuvalu, Uruguay, Vanuatu, República Bolivariana de Venezuela y Yemen. y rurales, entre barrios centrales y marginales, entre hombres y mujeres, y entre ricos y pobres. ${ }^{64} \mathrm{Y}$ aún quedan 768 millones de personas que carecen de acceso a agua potable. ${ }^{65}$

Reconocer el derecho al agua en el más alto nivel del ordenamiento jurídico del Estado - como lo hizo muy ejemplarmente la República Oriental del Uruguay- es una de las formas de adecuar la legislación nacional al derecho internacional de los derechos humanos con el fin de hacerlos efectivos, de conformidad con la obligación que surge, en este sentido, de varios instrumentos internacionales. ${ }^{66}$

Sin embargo, aún son pocas las Constituciones que reconocen específicamente y autónomamente el derecho al agua, ${ }^{67}$ imponiendo obligaciones al Estado, en el sentido de asegurar la disponibilidad, calidad y accesibilidad de tan preciado recurso, con carácter universal. Esas referencias constitucionales pueden ser luego desarrolladas por la normativa infraconstitucional (los términos en que la mayoría de estos preceptos están redactados implican la necesidad del Estado de adoptar disposiciones que lo especifiquen), incorporadas al discurso político (la inclusión del derecho al agua en el más alto rango normativo importa también un compromiso político al respecto), e invocadas ante los tribunales de justicia (las obligaciones contenidas en los preceptos constitucionales pueden exigirse directamente ante los órganos jurisdiccionales).

\section{El DERECHO AL AGUA EN LOS TRIBUNALES ARGENTINOS}

Si bien el derecho al agua como tal, autónomamente, no se encuentra reconocido de manera expresa en el nivel constitucional federal argentino, a partir de la reforma constitucional de 1994 que acarreó una ampliación considerable, aunque asistemática ${ }^{68}$ de los derechos, se puede sostener que este derecho aparece, aunque de modo indirecto, garantizado con rango normativo supremo a través de los instrumentos

64. Véase http://www.who.int/mediacentre/factsheets/fs290/es 65. Véase Avances en Saneamiento y Agua Potable Actualización del 2013. Programa de Monitoreo Conjunto oms/unicef.

66. $C f$. U.N. PACTO INTERNACIONAL DE DERECHOS CIVILES y Políticos, supra, nota 6. Artículo 2 y Artículo 2.1; A.G. Res. 2200A(xxi), supra, nota 23. Artículo 2.2., Pacto Internacional de Derechos Civiles y Políticos.

67. Las de Bolivia, Congo, Ecuador, Etiopía, Gambia, Kenia, México, Nigeria, Sudáfrica, Uganda, Uruguay y Zambia.

68. Humberto Quiroga Lavié, Miguel Ángel Benedetti y María de las Nieves Cenicacelaya. Derecho constitucional argentino. Rubinzal-Culzoni. (2009). 
internacionales sobre derechos humanos que gozan de jerarquía constitucional y que, como ya se anotó, tutelan implícitamente este derecho.

Así lo han ido entendiendo los jueces en diversos fallos de distintas jurisdicciones y de diferentes instancias, quienes la mayoría de las veces, con invocación del derecho internacional de los derechos humanos que hoy forma parte del bloque de constitucionalidad, ${ }^{69}$ han dado curso a diversos planteos en torno al derecho al agua, reafirmando así su exigibilidad y su justiciabilidad.

En este sentido, el acceso al agua se ha ido consolidando pretorianamente como derecho humano, ${ }^{70}$ vinculado a un nivel de vida adecuado y con ello, a la satisfacción de otros derechos humanos. ${ }^{71}$

Conforme a lo anterior, se ha establecido que el Estado, a través del Poder Judicial, tiene la obligación de asegurar ese derecho fundamental, ${ }^{72}$ incluso por medios alternativos si fuese necesario, dado su carácter de esencial para la vida $^{73}$ e insustituible. ${ }^{74}$

69. Según el artículo 75 inciso $22 \mathrm{cN}$, tienen jerarquía constitucional, sin derogar artículo alguno de la Constitución y entendiéndoselos complementarios de los derechos y garantías por ella reconocidos, 11 instrumentos internacionales sobre derechos humanos, a saber: Declaración Americana de los Derechos y Deberes del Hombre; Declaración Universal de Derechos Humanos; Convención Americana sobre Derechos Humanos; Pacto Internacional de Derechos Económicos, Sociales y Culturales; Pacto Internacional de Derechos Civiles y Políticos y su Protocolo Facultativo; Convención sobre la Prevención y la Sanción del Delito de Genocidio; Convención Internacional sobre la Eliminación de todas las Formas de Discriminación Racial; Convención sobre la Eliminación de todas las Formas de Discriminación contra la Mujer; Convención contra la Tortura y otros Tratos o Penas Crueles, Inhumanos o Degradantes; y Convención sobre los Derechos del Niño. Además, también gozan de ese estatus aquellos otros instrumentos que, con una mayoría agravada, el Congreso decida dotar de jerarquía suprema. Hasta el momento, tres: Convención Interamericana sobre Desaparición Forzada de Personas, Convención sobre la Imprescriptibilidad de los Crímenes de Guerra y de los Crímenes de Lesa Humanidad y Convención sobre los Derechos de las Personas con Discapacidad.

70. Caso Club Defensores de Torino c/ Aguas de Corrientes SA. Cámara de Apelaciones en lo Civil y Comercial de Corrientes, Sala IV, (24 de febrero de 2012); "Negrelli, Oscar R. y otro c/ Poder Ejecutivo y otro", Cámara de Apelaciones en lo Contencioso Administrativo de La Plata, 20 de noviembre de 2012.

71. Caso "Benítez, M. y otros c/ Municipalidad de Neuquén y otro", Cámara de Apelaciones Civil, Comercial, Laboral y de Minería de Neuquén, Sala I, 5 de octubre de 2012.

72. Caso "Vallejos Ripoll, Carlos M. c/ Aguas de Corrientes SA", Cámara de Apelaciones Civil y Comercial de Corrientes, Sala IV, 6 de mayo de 2009.

73. Caso "Asociación Civil por la Igualdad y la Justicia (ACIJ) c/ Ciudad de Buenos Aires", Cámara de Apelaciones Contencioso Administrativo y Tributario, Ciudad Autónoma de Buenos Aires, Sala I, 18 de julio de 2007.

74. Caso "Santino, Vicente Alberto c/ Aguas Argentinas sA s/ amparo", Cámara Nacional Civil y Comercial Federal, Sala 1.a , 22 de octubre de 2002
Así, en más de una ocasión, se ha ordenado garantizar a barrios marginales o a población de escasos recursos el suministro de agua potable mediante camiones cisterna. ${ }^{75}$

La maquinaria jurisdiccional también se ha puesto en marcha con el fin de tutelar el derecho a la salud, cuando este se ha visto en peligro en virtud de la calidad del agua, ordenándose, por ello, la entrega en forma gratuita y diaria a cada usuario y en su domicilio de una cantidad de agua envasada suficiente para atender sus necesidades más vitales. ${ }^{76}$ Esto en razón a que, por ejemplo, la suministrada habitualmente por red a la población presentaba en su composición físico-química una concentración excesiva de algunos elementos que la tornaban no apta para el consumo humano, conforme al Código Alimentario $;^{77}$ o bien porque se presumía su contaminación proveniente de una planta industrial cercana, cuya clausura preventiva, además, fue ordenada ${ }^{78} \mathrm{o}$ causada por el deficiente funcionamiento de una planta depuradora de aguas residuales, ${ }^{79}$ disponiéndose adicionalmente, en este último caso, la construcción de una planta eficiente de tratamiento sanitario de efluentes. ${ }^{80}$

75. Casos "s.N.C. c/ Aguas de Formosa SA", Juzgado de $1 .{ }^{\text {a }}$ Instancia Civil y Comercial N. ${ }^{\circ} 1$ de Formosa, 17 de mayo de 2001 y "Asociación Civil por la Igualdad y la Justicia (ACIJ) c/ Ciudad de Buenos Aires", Cámara de Apelaciones Contencioso Administrativo y Tributario, Ciudad Autónoma de Buenos Aires, Sala I, 18 de julio de 2007.

76. Casos "Asociación Ambientalista del Sur c/ Azurix SA", Juzgado en lo Civil y Comercial N. ${ }^{\circ} 1$ de Bahía Blanca, 26 de abril de 2000; "Argañaraz, Francisco, Godoy, Juan Carlos y otros" c/ Aguas Cordobesas SA, Cámara 8. ${ }^{a}$ de Apelaciones Civil y Comercial de Córdoba, 24 de marzo de 2004.

77. Casos "Conde, Alberto José Luis c/ Aguas Bonaerenses SA s/ amparo", Cámara en lo Contencioso Administrativo de San Nicolás, 30 de octubre de 2008; "Boragina, Juan Carlos; Miano, Marcelo Fabián e Iudica, Juan Ignacio c/ Municipalidad de Junín s/ amparo", Suprema Corte de la Provincia de Buenos Aires, 15 de julio de 2009; "Florit, Carlos Ariel y otros c/ Provincia de Buenos Aires y Aguas Bonaerenses sA s/ amparo", Juzgado en lo Contencioso Administrativo N. ${ }^{\circ} 1$ de Trenque Lauquen, 6 de julio de 2010; y "Solari, Marta y otros s/ amparo - Incidente de apelación", Cámara en lo Contencioso Administrativo de La Plata, 10 de agosto de 2010. 78. Caso "Vela, Darío René y otros c/ Massuh sA y otros", Juzgado en lo Contencioso Administrativo N. ${ }^{\circ} 1$ de La Plata, 9 de setiembre de 2009.

79. Caso "Marchisio, José Bautista y otros c/ Superior Gobierno de la Provincia de Córdoba y otros/ amparo" (Caso "Chacras de la

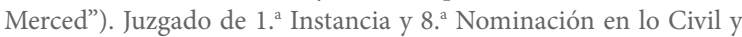
Comercial de Córdoba, 19 de octubre de 2004.

80. Caso "Merlo, Apolinario c/ Aguas de Corrientes SA, Administración de Obras Sanitarias de Corrientes y Estado de la Provincia de Corrientes s/ medida autosatisfactiva (conocimiento)", Cámara de Apelaciones en lo Civil y Comercial, Sala IV, 1 de octubre de 2009 . 
Más aún, en un caso impulsado por el periódico de mayor circulación en Córdoba, en el que se cuestionaba la calidad del servicio de agua potable $-\mathrm{y}$ su posible contaminación- en algunos barrios de esa ciudad del centro del país, y el derecho de acceso a la información pública - como desprendimiento de la libertad de prensa y del derecho a la información en general-, el juez interviniente recordó palabras de la Corte Interamericana de Derechos Humanos, en el sentido de que la libertad de expresión es una "piedra angular" del sistema democrático. ${ }^{81}$ Se reafirmaba, de este modo, la idea de la interdependencia de todos los derechos, como muy acertadamente lo hizo el juez de la Corte con sede en San José de Costa Rica, Sergio García Ramírez, en un voto concurrente y razonado, al que ya se hizo referencia más arriba.

Dada la vital importancia que reviste el agua potable, en varias ocasiones se ha establecido la improcedencia de cortar el suministro domiciliario y como consecuencia de ello, negar absolutamente su provisión, con fundamento en la mera falta de pago, ${ }^{82}$ a veces motivada por la incapacidad económica de las familias. ${ }^{83}$ Con mayor razón aún si habitan en zonas donde las napas están contaminadas, no resultando potable el agua de pozo, ${ }^{84}$ por cuanto ello "implicaría la privación de un bien invalorable, irremplazable y vital para la subsistencia" y "un menoscabo y pronunciado detrimento de un digno y mínimo estándar de calidad de vida". ${ }^{85}$ En este sentido, hace ya tiempo que se percibe que el servicio público de agua potable es una actividad estrictamente vinculada al bienestar general, así como que de su calidad y eficiencia depende, en gran medida, la dignidad de las personas. ${ }^{86}$

81. Caso "La Voz del Interior SA c/ ERSeP s/ amparo", Juzgado Civil y Comercial N. ${ }^{\circ} 48$ de Córdoba, 26 de agosto de 2004.

82. Casos "Kobylansky, Mercedes N. c/ Dalvian SA", Cámara 2. de Apelaciones Civil, Comercial, de Minas, de Paz y Tributaria de Mendoza, 15 de junio de 2000; "Silva Nélida Crispina c/Aguas de Formosa sa s/sumario", Juzgado Civil y Comercial N. ${ }^{\circ} 1$ de Formosa, 17 de mayo de 2001; "Ronchi, Pablo J. c/ Aguas Argentinas SA s/ Amparo (incidente apelación)", Cámara Federal de Apelaciones de La Plata, 7 de febrero de 2002; "Ramos, Elsa Mirta c/ Sociedad Aguas del Tucumán”, Cámara de Apelaciones Contencioso Administrativo de Tucumán, Sala I, 25 de febrero de 2010.

83. Caso "Vivacqua, Julio c/ Cooperativa Ltda. de Consumo de Electricidad y Servicios de Olavarría”, Cámara de Apelaciones Civil y Comercial de Azul, Sala II, 26 de marzo de 2002.

84. Caso "Usuarios y Consumidores en Defensa de sus Derechos Asociación Civil c/ Aguas del Gran Buenos Aires SA", Juzgado de Paz de Moreno, 21 de agosto de 2002.

85. Caso "Asociación de Fomento Barrio Autódromo c/ O.s.s.E. s/ medidas cautelares", Cámara de Apelaciones en lo Civil y Comercial de Mar del Plata, Sala 2. ${ }^{\text {a }} 20$ de marzo de 2003.

86. Caso "Conet c/ Cooperativa de Luz y Fuerza de Villa de Soto", Tribunal Superior de Justicia de la Provincia de Córdoba, Sala Civil y Comercial, 5 de marzo de 1991.
Los aumentos desproporcionados en las tarifas del servicio de provisión domiciliaria de agua que, como dijimos más arriba, violan el deber de respeto que los Estados han asumido en relación con el derecho al agua, también han dado lugar a pronunciamientos judiciales destacables. Así, se ha habilitado a suspender la obligación de pago por parte de usuarios de las facturaciones emitidas por una empresa por tener un incremento injustificado. ${ }^{87}$

Un caso que, con muchos vaivenes, ya lleva varios años en discusión en los estrados judiciales de la Provincia de Buenos Aires, es el suscitado a partir de mayo del 2012, cuando el gobierno bonaerense dispuso un ajuste tarifario para el servicio de agua potable y cloacas que presta la empresa estatal Aguas Bonaerenses Sociedad Anónima (ABSA), el cual alcanzaba incrementos de hasta el $180 \%$. La medida provocó fuertes protestas de los millones de usuarios de los 91 municipios del distrito más importante del país, en los que la empresa presta el servicio. En ese contexto, un diputado provincial y la defensora ciudadana de la ciudad capital se presentaron a la justicia solicitando suspender el nuevo régimen tarifario, en razón a haberse dispuesto sin la realización previa de una audiencia pública. El cuestionamiento fue avalado por un fallo en primera instancia, que luego fue revocado en la apelación. Los peticionantes insistieron ante la máxima instancia judicial provincial, quien sentenció la nulidad del decreto administrativo que permitió el aumento luego impugnado por no haberse "previsto ni garantizado, de algún modo previo y eficaz, la información y consecuente participación de los usuarios en la toma de decisión"; a la vez que ordenó la devolución a los usuarios de los montos extras cobrados, los que "se imputarán en futuras facturaciones" ${ }^{88}$ De todas formas, la Provincia de Buenos Aires ha recurrido ese fallo ante la Corte Suprema Federal, de manera que el caso se encuentra aún pendiente de resolución definitiva.

A su turno, la Corte Suprema de Justicia de la Nación, máximo órgano jurisdiccional argentino, también ha emitido en los últimos años pronunciamientos de valía en torno a la protección del recurso agua y a la garantía de acceso a este vital elemento.

La primera vez que se ocupó del tema fue en el 2007, en ocasión de resolver el - hasta ese momentoúnico caso sobre derechos de pueblos indígenas,

87. Caso "Defensor del Pueblo de Santiago del Estero c/ Aguas de Santiago SA", Superior Tribunal de Justicia de Santiago del Estero, 10 de marzo de 1999.

88. Caso "Negrelli, Oscar R. y otros c/ Poder Ejecutivo y otros s/ amparo. Recurso extraordinario de inconstitucionalidad e inaplicabilidad de ley", Suprema Corte de Justicia de la Provincia de Buenos Aires, 3 de diciembre de 2014 
originado a partir de una acción de amparo presentada por el Defensor del Pueblo de la Nación, a fin de que se condenase tanto a la provincia del Chaco como al Estado nacional, ante la grave situación de "exterminio silencioso, progresivo, sistemático e inexorable" que sufren las poblaciones originarias de esa región del nordeste del país, a garantizarles de manera continua y permanente una real y efectiva calidad de vida digna, tal como imponen la Constitución Nacional y los instrumentos internacionales sobre derechos humanos y la constitución provincial. Entendiendo que,

Corresponde al Poder Judicial de la Nación buscar los medios que permitan garantizar la eficacia de los derechos y evitar que estos sean vulnerados, como objetivo fundamental y rector a la hora de administrar y de tomar decisiones en los procesos que se someten a su conocimiento, sobre todo cuanto está en juego el derecho a la vida y a la integridad física de las personas.

Se alzó así el máximo tribunal como guardián y custodio de los derechos humanos a fin de evitar - ante la inactividad y omisión de los deberes de los órganos ejecutivos nacional y provincial- su desconocimiento y vulneración. Al hacerlo, señaló que no se trata de una intromisión indebida en las funciones de estos derechos, sino que pretende suplir sus omisiones para tutelar derechos. Y ordenó además a ambas jurisdicciones demandadas con plazo perentorio a que - entre otras medidas - proveyesen de agua potable a las comunidades afectadas e informasen sobre la ejecución de programas en esa dirección. ${ }^{89}$ En relación con lo último, desde entonces se vienen desarrollando audiencias con cierta periodicidad ante el Alto Tribunal a efectos de hacer un seguimiento de los esfuerzos realizados por los demandados en procura del cumplimiento cabal de la demanda judicial.

$\mathrm{Al}$ año siguiente, la Corte Suprema dictó una trascendente sentencia encaminada a mejorar la calidad de vida de unos cinco millones de personas que viven en torno a la cuenca hídrica más contaminada del país, la Cuenca Matanza-Riachuelo, la cual cuenta con una extensión de $65 \mathrm{~km}$ y abarca una superficie de $2240 \mathrm{~km}^{2}$, involucrando a catorce municipios de la Provincia de Buenos, además de la Ciudad Autónoma de Buenos Aires.

89. Caso "Defensor del Pueblo de la Nación c/ Estado Nacional y otra (Provincia del Chaco) s/ proceso de conocimiento", Corte Suprema de Justicia de la Nación, 18 de setiembre de 2007.
El pronunciamiento se produjo como respuesta a una demanda por daños y perjuicios y recomposición ambiental que interpuso un grupo de vecinos residentes en dicha cuenca contra el Estado Nacional, la Provincia de Buenos Aires, la Ciudad Autónoma de Buenos Aires y 44 empresas contaminantes. Luego de haber dictado una primera sentencia en el 2006, a través de la cual se requirió al Estado la presentación de un plan para limpiar la cuenca y recomponer el agua, el suelo y el aire, el cual sería discutido en audiencias públicas. ${ }^{90}$ Terminada esta fase, dictó, entonces, la última sentencia en $2008,{ }^{91}$ en la cual, no obstante señalar que los tres niveles de gobierno demandados eran conjuntamente responsables por la implementación del programa y el efectivo logro de los objetivos, determinó que la responsabilidad primaria recae en la recientemente creada Autoridad de Cuenca Matanza-Riachuelo (ACUMAR), ${ }^{92}$ fijándole plazos de realización y sanciones en caso de incumplimiento. Además, dejó en manos de un juez federal la ejecución de la sentencia y estableció un control sobre ella, en manos del Defensor del Pueblo, ${ }^{93}$ de las ong que intervinieron como terceros en la causa y de la Auditoría General de la Nación. ${ }^{94}$

90. Caso "Mendoza, Beatriz Silvia y otros c/ Estado Nacional y otros s/ daños y perjuicios (daños derivados de la contaminación ambiental del río Matanza-Riachuelo)", Corte Suprema de Justicia de la Nación, 20 de junio de 2006.

91. Caso "Mendoza, Beatriz Silvia y otros c/ Estado Nacional y otros s/ daños y perjuicios (daños derivados de la contaminación ambiental del río Matanza-Riachuelo)", Corte Suprema de Justicia de la Nación, 8 de julio de 2008.

92. Véase Ley 26.168. Por la cual se crea la Autoridad de Cuenca Matanza Riachuelo -ACUMAR-. Mayo 5 de 2012. во 05-12-2006.

93. En el Artículo 86 CN se lee: "El Defensor del Pueblo es un órgano independiente instituido en el ámbito del Congreso de la Nación, que actuará con plena autonomía funcional, sin recibir instrucciones de ninguna autoridad. Su misión es la defensa y protección de los derechos humanos y demás derechos, garantías e intereses tutelados en esta Constitución y las leyes, ante hechos, actos u omisiones de la Administración; y el control del ejercicio de las funciones administrativas públicas [...] El Defensor del Pueblo tiene legitimación procesal. Es designado y removido por el Congreso con el voto de las dos terceras partes de los miembros presentes de cada una de las Cámaras". Cf. Constitución de la Nación Argentina. [Const.]. (Argentina).

94. Cf. Id. En el artículo 85 CN se lee: "El examen y la opinión del Poder Legislativo sobre el desempeño y situación general de la administración pública estarán sustentados en los dictámenes de la Auditoría General de la Nación [...] Tendrá a su cargo el control de legalidad, gestión y auditoría de toda la actividad de la administración pública centralizada y descentralizada, cualquiera fuera su modalidad de organización, y las demás funciones que la ley le otorgue. Intervendrá necesariamente en el trámite de aprobación o rechazo de las cuentas de percepción e inversión de los fondos públicos. 
Se trata de una sentencia colectiva atípica, de carácter declarativo y de ejecución, que contiene por un lado, una condena general con deberes a cumplir por la Autoridad de Cuenca y, por otro, establece las bases de la ejecución de la sentencia, mediante un sistema de control institucional. Entre otras medidas, se ordena la presentación en forma pública - actualizada trimestralmente- del estado del agua y las napas subterráneas de la cuenca, informar también públicamente sobre los planes de obras y tareas de expansión de la red de agua potable, y elaborar un diagnóstico de patologías producidas por la contaminación del agua. Todo ello, llamativamente, con fundamento exclusivo en normas de derecho interno (constitucionales y legales), sin invocar el derecho internacional de los derechos humanos que, como hemos visto, contienen pautas y límites de actuación para los poderes políticos que resultarían pertinentes y absolutamente aplicables a este caso.

Un serio y extendido problema que presenta el agua para consumo humano en Argentina es que el país tiene - debido a procesos geológicosgrandes áreas arsenicales (unos 435000 kilómetros cuadrados), las cuales ubican al país como uno de los que cuenta con mayor población expuesta a este fenómeno en el mundo (unos cuatro millones de personas corren riesgo de enfermarse e incluso morir por esta causa).

Por ello, en el 2007 y en consonancia con lo indicado por la Organización Mundial de la Salud, el Código Alimentario Argentino redujo de $0,05 \mathrm{mg} / \mathrm{l}$ a $0,01 \mathrm{mg} / \mathrm{l}$ el máximo de arsénico permitido en el agua de red, instando, además, a que las empresas proveedoras adecuaran sus plantas en el plazo de cinco años. ${ }^{95}$

En varios casos, vecinos de distintos distritos bonaerenses reclamaron judicialmente - con éxito- la provisión de agua en bidones hasta tanto se diese una solución estructural al problema del agua suministrada a través de la red con altos niveles de arsénico. Una de esas demandas fue un amparo incoado por un grupo de veinticinco vecinos de la Ciudad de 9 de Julio, en el centro de la Provincia de Buenos Aires, a fin de que se obligase a la empresa ABSA a comenzar los trabajos y tareas necesarios que permitan adecuar la calidad y potabilidad del agua de uso domiciliario, aunque también extendieron su demanda a la Provincia, "en virtud de que

95. Véase Resolución Conjunta 68/2007 y 196/2007. [Secretaría de Políticas, Regulación y Relaciones Sanitarias y Secretaría de Agricultura, Ganadería, Pesca y Alimentos]. es titular del dominio acuífero". Luego de recorrer todas las instancias de grado, en las que los amparistas resultaron victoriosos, el caso llegó a la Corte Suprema Federal que reconoció por vez primera el derecho humano al agua, no obstante dejó sin efecto la sentencia apelada por entender que no se había cumplido con las reglas procedimentales de los amparos colectivos y, con ello, vulnerado el derecho de defensa de la demandada. ${ }^{96}$

En efecto, más allá de los objeciones formales planteadas para descalificar el fallo recurrido por ABSA, considerando "que en el caso, existe la necesidad de una tutela judicial urgente, en la medida que está en juego el derecho humano de acceso al agua potable, la salud y la vida de una gran cantidad de personas y al mismo tiempo existe una demora de la demandada en la solución definitiva de esta situación”, mantuvo la medida cautelar ordenada por el juez de primera instancia que obligaba al suministro de agua potable (en bidones) a los afectados en "la cantidad necesaria para satisfacer las necesidades básicas de consumo, higiene personal, y limpieza de manos y alimentos y cocción de estos en una ración no menor a 200 litros por mes".

En resumen, la Corte Suprema entendió que la contaminación del agua con arsénico que se suministra por la red no es un problema de cada uno de los habitantes, sino que es un problema comunitario que, para su mejor solución, debe ser tratado en un proceso colectivo. Con invocación del derecho internacional de los derechos humanos, recordó que el derecho humano al agua es indispensable para vivir dignamente y es condición previa para la realización de otros derechos humanos, el cual debe ser asegurado por diversos medios, también judicialmente, resultando el proceso colectivo el que mejor garantiza su realización.

\section{CONCLUSiones}

Más allá de su escaso y parcial reconocimiento jurídico, el derecho de acceder a agua segura es, sin hesitación alguna, y aunque parezca una obviedad concluir esto, un derecho fundamental. Tampoco huelga reafirmar que el acceso equitativo a las necesidades mínimas de agua segura es una condición previa y necesaria para el efectivo goce de todos los

\footnotetext{
96. Caso "Kersich, Juan Gabriel y otros c/ Aguas Bonaerenses y otros s/ amparo", Corte Suprema de Justicia de la Nación, 2 de diciembre de 2014.
} 
derechos humanos, reafirmando así su indivisibilidad e interdependencia, e incluso asumiendo, quizá, un rol ejemplar de superación de la discutida categorización de "generaciones" de derechos.

De lo anterior se derivan varias obligaciones estatales, incluyendo el otorgamiento de facilidades para acudir ante las instancias judiciales, a fin de que en caso de incumplimiento se efectivice su plena justiciabilidad.

Destacadas decisiones de la justicia argentina como las que se han expuesto sucintamente en el presente trabajo, han ido contribuyendo, paulatinamente, al respeto, protección y realización de este derecho.

\section{REFERENCIAS}

A.G. Res. 2200A(xxi). PACTO INTERnaCional DE DERECHOS ECONÓMICOS, SOCIALES Y CULTURALES. (Enero 3 de 1976).

Antonio Enrique Pérez Luño. Concepto y concepción de los derechos humanos. Revista Doxa 4. 1987. Págs. 47-66.

Carlos Urquilla. LA JUSTICIABILIDAD DIRECTA DE LOS DERECHOS ECONÓMICOS, SOCIALES Y CULTURALES. InStituto Interamericano de Derechos Humanos. (2008).

Constitución de la República Italiana [Const.]. (Italia).

Convención Americana sobre Derechos Humanos-Pacto de San Juan de Costa Rica. (Noviembre 22 de 1969).

Convención Americana sobre Derechos Humanos (CADH). Preámbulo. Protocolo adicional a LA CONVENCIÓN AMERICANA SOBRE DERECHOS HUMANOS EN MATERIA DE DERECHOS ECONÓMICOS, SOCIALES Y CUlturales. (Noviembre 17 de 1988).

Comité Desc. Observaciones generales adoptadas Por EL COMITÉ DE DERECHOS ECONÓMICOS, SOCIALES Y CULTURALES. (1990).

Corte Interamericana de Derechos Humanos. Condición JURÍDICA Y DERECHOS HUMANOS DEL NIÑO. Opinión Consultiva oc-17/02. (Agosto 28 de 2002).

Christian Courtis. La prohibición de regresividad en materia de derechos sociales: apuntes introductorios. Comp. Christian Courtis. Ni UN PASO ATRÁs. LA PROHIBICIÓN DE REGRESIVIDAD EN MATERIA DE DERECHOS sociales. Editores del Puerto. (2006). Págs. 6-28.

Cidh. Informe del Comisionado Víctor Abramovich SOBRE EL ACCESO A LA JUSTICIA COMO GARANTÍA DE LOS DERECHOS ECONÓMICOS, SOCIALES Y CULTURALES. ESTUdio DE LOS ESTÁNDARES FIJADOS POR EL SISTEMA INTERAMERICANO DE DERECHOS HUMANOS. OEA/Ser.L/V/II.129 Doc. 4. (Septiembre 7 de 2007).
Cristina Monereo. Una teoría de los derechos sociales es posible. Coords. Gerardo Pisarello y Vanesa Valiño. HerRamientas PARA LA DEFENSA DE los DERECHOS ECONÓMICOS, SOCIALES Y CULTURALES. Observatorio DESC. (2006). Págs. 9-27.

Humberto Quiroga Lavié, Miguel Ángel Benedetti y María de las Nieves Cenicacelaya. Derecho constitucioNAL ARGENTINO. Rubinzal-Culzoni. (2009).

Ibrahima Fall. La protección de los derechos humanos en el horizonte del Siglo XXI. Revista Relaciones InTERNACIONALES 8. 1995. Págs. 23-48.

Karel Vasak. Les mysterieux droits economiques de l'homme. Comp. Renato Zerbini Ribeiro. Rumbos DEL DERECHo INTERNACIONAL DE LOS DERECHOS HUMANOS. TOMO III. (2005). Págs. 253-265.

Ligia Bolívar. Derechos económicos sociales y culturales: derribar mitos, enfrentar retos, tender puentes. EsTudIOs BÁsicos DE DERECHOS HUMANO. Tomo v. Instituto Interamericano de Derechos Humanos. (1996). Págs. 86-136.

Ley 26.168. Por la cual se crea la Autoridad de Cuenca Matanza Riachuelo -ACUMAR-. Mayo 5 de 2012. Bo 0512-2006.

Lynn Hunt. LA INVENCión DE LOS DERECHOS HUMANOS. Tusquets. (2010).

Magdalena Sepúlveda. La interpretación del Comité de Derechos Económicos, Sociales y Culturales de la expresión "progresivamente". NI UN PASO ATRÁs. LA PROHIBICIÓN DE REGRESIVIDAD EN MATERIA DE DEReChos SOciales. CEls, Editores del Puerto. (2006). Págs. 117-150.

Mónica Pinto. Los derechos económicos, sociales y culturales y su protección en el sistema universal y en el sistema interamericano. REVISTA DEL INSTITUTO INTERAMERICANO DE DERECHOS humANOS. (Vol. 40, 2004). Págs. 25-86.

Pedro Nikken. El concepto de derechos humanos. Estudios BÁsICOS DE DERECHOS HUMANOS. Tomo I. Instituto Interamericano de Derechos Humanos (1994). Págs. 15-37.

Pedro Nikken. LA PROTECCión INTERnACIONAL DE LOS DERECHOS HUMANOS: SU DESARROLLO PROGRESIVO. Instituto Interamericano de Derechos Humanos. Civitas. (1987).

Fabián Salvioli. Algunas tendencias sobre derechos humanos en las relaciones internacionales y el derecho internacional de la posguerra fría. ANUARIO DE RELACIONES INTERNACIONALES 1995/96. Centro de Estudios Avanzados, Universidad de Córdoba. (1997). Págs. 21-80. 
Oea. Declaración Americana De Derechos y Deberes DEL HOMBRE. (1948).

Philippe Texier. Exigibilidad de los derechos económicos, sociales y culturales en el sistema universal. CONSTRUYENDO UNA AGENDA PARA LA JUSTICIABILIDAD DE LOS DERECHOS SOCIALES. CEJIL. (2004). Págs. 13-24.

Sergio García Ramírez. Protección jurisdiccional internacional de los derechos económicos, sociales y culturales. CuEsTiones Constitucionales 9. 2003. Págs. 127-157.

Susana Albanese. Indivisibilidad e interdependencia de los derechos. Coord. Germán Bidart Campos. EconomíA, CONSTITUCIÓN Y DERECHOS SOCIALES. Ediar. (1997). Págs. 9-39.

U.N. Comisión de la Condición Jurídica y Social de la Mujer. CONVENCIÓN SOBRE LA ELIMINACIÓN DE TODAS LAS FORMAS DE DISCRIMINACIÓN CONTRA LA MUJER. (1946).

U.N. Res. 217A(III). Declaración Universal DE DERECHOS humanos. (Diciembre 10 de 1948).
U.N. PaCto INTERnacional De DeRechos CiVILES Y POLÍTICOS. A/RES/21/2200. (1966).

U.N. Comisión de Derecho internacional. Convención DE VIENA SOBRE EL DERECHO DE LOS TRATADOS. A/ CONF.39/27 (1969).

U.N. LIMBURG PRINCIPLES ON THE IMPLEMENTATION OF THE INTERNATIONAL COVENANT ON ECONOMIC, SOCIAL AND CULTURAL RIGHTS. E/CN.4/1987/17. (1987).

U.N. Commission on Human Rights. THE RIGHT TO FOOD. E/ CN.4/sub.2/1987/23. (Marzo 7 de 1988).

U.N. Danilo Türk. The REALization of ECONOMIC, SOCIAL AND CULTURAL RIGHTS. E/CN.4/Sub.2/1992/16. (Julio 3 de 1992).

U.N. DeClaración y PROGRAMA DE ACCIÓN DE VIENA. A/ CONF.157/23. (Julio 12 de 1993).

Víctor Abramovich y Christian Courtis. Los DEREChOs SOCIALES COMO DERECHOS EXIGIBLES. Trotta. (2002). 